\title{
Illegitimate Mating in Paramecium bursaria and the Basis for Cell Union
}

\author{
BY L. L. LARISON AND R. W. SIEGEL \\ Department of Zoology, University of California, Los Angeles, U.S.A.
}

(Received 24, April 1961)

\begin{abstract}
SUMMARY
Cells from stock Wu-67 of Paramecium bursaria, syngen 1, can be induced to conjugate inter se (self) if they have made brief but transitory contact with cells of a complementary mating type; in mixtures consisting of marked cells of Wu-67 and cells of a complementary mating type both interclonal and intraclonal (Wu-67 $\times$ Wu-67) conjugations were recognized. Unmixed cultures of Wu-67 never self nor could selfing be induced in other ways. In contrast to normal conjugation the intraclonal matings are illegitimate because they occur between cells expressing a common mating-type specificity. These and other facts are considered in light of Weiss's hypothesis about cell unions; it is postulated that a primary specific surface reaction dependent upon mating-type complementarity serves to elicit a secondary non-specific ('holdfast') reaction leading to the completion of conjugation. In cells from $\mathrm{Wu}-67$ the sites of secondary reaction are held to be precociously or more readily activated than in normal cells and, when two such activated cells are apposed, illegitimate mating may occur. Under certain circumstances then, cellular adhesion and conjugation may be independent of primary mating-type complementarity and dependent instead upon the availability of secondary non-specific attachment sites.
\end{abstract}

\section{INTRODUCTION}

In Paramecium conjugation takes place when sexually mature cells of complementary mating types are brought together under appropriate environmental conditions. Although cells which belong to a common mating type do not normally conjugate among themselves, and reproductive isolation is the primary basis for the definition of physiological species (syngens or varieties), exceptions to these rules have been noted by various workers. Such findings are of intrinsic interest but they also seem pertinent to more general problems such as the basis for adhesions among somatic cells and the nature of sexuality-how do artificially dissociated somatic cells become properly reoriented and how are cellular changes leading to meiosis and fertilization induced? The observations and experiments reported in the present paper are concerned with illegitimate (intraclonal) conjugations in a mutant clone of Paramecium bursaria. The data are consistent with an hypothesis put forward by Weiss (1960), for they suggest that the cellular pairing, which leads to conjugation, is normally a consequence of a primary specificity and a secondary non-specific interaction of cell surfaces.

Previous investigations reported by Sonneborn (1942), Metz (1954) and Hiwatashi (1955) led to the conclusion that the mating reaction in Paramecium involves two 
distinct and separable mechanisms. In analyses of the primary specific mating reaction mechanism, Metz and co-workers and Hiwatashi showed that cells belonging to a single clone can mate amongst themselves after some of the individuals have made transient contacts with cells of a complementary mating type. The most recent and provocative work along these lines is that of Hiwatashi (1958) and Miyake (1956, 1958, 1960) who induced conjugations among normally incompatible cells of Paramecium caudatum, $\boldsymbol{P}$. aurelia and $\boldsymbol{P}$. multimicronucleatum by the use of chemical agents. In all of these studies, the question arises as to whether or not contact with a complementary cell or chemical treatment causes a specific change in mating type. If a change in mating type does occur, induced intraclonal matings may occur between animals of complementary mating types and should be termed legitimate. One contribution of the present analysis is the resolution of this question for a particular case. A brief report of these results has appeared in abstract form (Siegel \& Larison, 1960).

\section{METHODS}

Standard clones of Paramecium bursaria, representing each of the four complementary mating types (designated A, B, C, D) known for syngen 1 of this species and described in detail elsewhere (Siegel, 1958; Siegel \& Larison, 1960) were used in the present work. Stocks Wu-67, JP-55 and NC-64 were kindly furnished by Professor T. T. Chen. In $\boldsymbol{P}$. bursaria, each animal cell normally carries several hundred chlorella cells in hereditary endosymbiosis giving the paramecium a green appearance. When cultures of $\boldsymbol{P}$. bursaria are allowed to reproduce rapidly in darkness the fission rate of the paramecia will exceed that of the symbiotic algae, and the number of algae/animal will rapidly diminish until sublines lacking algae are produced (Siegel, 1960). For convenience we shall designate such cells as 'white'. Separate cultures consisting of parasitized (green) and of asymbiotic or chlorella-less (white) paramecia, readily distinguishable from one another, were prepared for each stock and used in the detection of legitimate interclonal and illegitimate intraclonal conjugations. When a culture of green cells of one mating type is mixed with a culture of white cells of another mating type, green $\times$ white pairings are interclonal whereas green $\times$ green and white $\times$ white pairings are intraclonal. The sexuality of the paramecia is known to be independent of the presence of endosymbionts (Ehret, 1953). The origins and properties of the stocks and their derived sublines are listed in Table 1.

It should be emphasized that these stocks will conjugate only when mixed with sexually reactive cells of a complementary type. The capacity of stock Wu-67 to undergo illegitimate (Wu-67 $\times \mathbf{W u - 6 7 )}$ as well as legitimate (interstock) conjugation following its mixture with a clone of a complementary mating type is described in a later section. The occurrence of illegitimate pairing was found to be independent of the symbiotic association.

Phase-contrast microscopical examination of living paramecia from stock Wu-67 showed them to be cytologically normal, containing a single micronucleus and a single macronucleus, two contractile vacuoles, gullet, etc. (see Wichterman, 1953).

Methods for cultivating and handling Paramecium bursaria as already described (Jennings, 1939; Ehret, 1953; Siegel, 1960) were used; they follow closely the standard procedures for $P$. aurelia (Sonneborn, 1950). Experimental cells were 
obtained from mass cultures previously grown at $25^{\circ}$ and subjected to diurnal periods of artificial white light (100 ft. candles). Under these conditions the cells reached a peak of sexual reactivity at noon (Ehret, 1953) and matings were initiated at that time. The mixtures were kept at $25^{\circ}$ and observed for conjugations at 4 p.m. of the same day.

Mating types of unknown cultures were determined by testing separate samples of each with cells of the four standard mating types. The unknown was classified as a particular type if it failed to mate with the standard of that type, but was able to mate with cells of the remaining three types.

Table 1. The properties, origins and designations of the stocks of Paramecium bursaria

\begin{tabular}{|c|c|c|c|c|}
\hline Stock & Natural source & $\begin{array}{l}\text { Mating } \\
\text { type }\end{array}$ & $\begin{array}{l}\text { Endosymbiotic } \\
\text { chlorella }\end{array}$ & Designation \\
\hline 8 & Malibu Lake, California & $\mathbf{A}$ & $\begin{array}{l}\text { Present } \\
\text { Absent }\end{array}$ & $\begin{array}{l}8 A-g \\
8 A-w\end{array}$ \\
\hline Wu-67 & Shanghai, China & $\mathbf{A}$ & $\begin{array}{l}\text { Present } \\
\text { Absent }\end{array}$ & $\begin{array}{l}\text { Wu-67A-g } \\
\text { Wu-67A-w }\end{array}$ \\
\hline 25 & Malibu Lake, California & B & $\begin{array}{l}\text { Present } \\
\text { Absent }\end{array}$ & $\begin{array}{l}25 \mathrm{~B}-\mathrm{g} \\
25 \mathrm{~B}-\mathrm{w}\end{array}$ \\
\hline 32 & Malibu Lake, California & C & $\begin{array}{l}\text { Present } \\
\text { Absent }\end{array}$ & $\begin{array}{l}32 C-g \\
32 C-w\end{array}$ \\
\hline 34 & Fish Canyon, California & $\mathrm{C}$ & $\begin{array}{l}\text { Present } \\
\text { Absent }\end{array}$ & $\begin{array}{l}\text { 34C-g } \\
\text { 34C-w }\end{array}$ \\
\hline JP-55 & Sapporo, Japan & $\mathbf{C}$ & $\begin{array}{l}\text { Present } \\
\text { Absent }\end{array}$ & $\begin{array}{l}\text { JP-55C-g } \\
\text { JP-55C-w }\end{array}$ \\
\hline 3 & Malibu Lake, California & $\mathbf{D}$ & $\begin{array}{l}\text { Present } \\
\text { Absent }\end{array}$ & $\begin{array}{l}3 D-g \\
3 D-w\end{array}$ \\
\hline NC-64 & North Carolina & D & $\begin{array}{l}\text { Present } \\
\text { Absent }\end{array}$ & $\begin{array}{l}\text { NC-64D-g } \\
\text { NC-64D-w }\end{array}$ \\
\hline
\end{tabular}

\section{RESULTS}

The initial observation on conjugations involving cells from stock $\mathrm{Wu}-67$ demonstrated their unique ability to mate among themselves. Table 2 shows the results of mixing representative stocks of syngen 1 in all possible combinations of twos; in each combination, one of the cultures consisted of green cells while the other consisted of white cells; thus the origin of each paired cell could be ascertained. As expected, in mixtures of cultures belonging to a common mating type no pairing occurred, while in mixtures of cells of complementary mating types numerous pairs formed, each pair consisting of a cell from each of the two complementary stocks. In striking contrast mixtures of cells from stock $\mathrm{Wu}-67$ with cells of a complementary mating type always yielded exceptional pairs, both mates originating from stock Wu-67, in addition to interstock pairs. Such illegitimate pairing never occurred in unmixed control cultures of stock Wu-67.

Detailed observations were made on those mating reactions which led to the formation of Wu-67 $\times$ Wu-67 pairs. The cells of stock Wu-67 were readily distinguished from those of the complementary mating type by the presence of chlorellae. Upon mixing cultures of complementary mating types, the usual swimming movements serve to bring two individuals into accidental contact; the cells immediately 
'stick' if they belong to complementary types. These initial unions involve any part of the ciliated surface and so are irregular; they were easily disrupted by picking up and then expelling the cells with the aid of a micropipette. In agreement with the observations of others, a third and fourth cell were seen to adhere to the two initial cells and this continued until, a few minutes after mixture, large masses containing $\mathbf{1 0 0}$ or more individuals were formed. When the clumps were artificially broken up soon after they had formed, many loosely joined pairs were observed. Since neither green $\times$ green nor white $\times$ white unions were found, it must be con-

Table 2. The occurrence of interclonal and intraclonal conjugation among stocks representing the four mating types of Paramecium bursaria, syngen I. Cells were ' marked' by the presence (green) or absence (white) of symbiotic algae

\begin{tabular}{|c|c|c|c|c|c|c|c|c|c|}
\hline \multirow[b]{3}{*}{$\begin{array}{c}\text { Mating } \\
\text { type }\end{array}$} & \multirow[b]{3}{*}{ Stock } & \multicolumn{8}{|c|}{ Cells contain chlorellae-'green' } \\
\hline & & \multicolumn{2}{|c|}{ A } & \multirow{2}{*}{$\begin{array}{c}\text { B } \\
\text { 25 B-g }\end{array}$} & \multicolumn{3}{|c|}{ C } & \multicolumn{2}{|c|}{$\mathbf{D}$} \\
\hline & & $\begin{array}{c}\text { Wu- } \\
\text { 67 A-g }\end{array}$ & $8 A-g$ & & $32 \mathrm{C}-\mathrm{g}$ & 34C-g & $\begin{array}{c}\text { JP- } \\
55 \text { C-g }\end{array}$ & $3 D-g$ & $\begin{array}{l}\text { NC- } \\
64 \mathrm{D}-\mathrm{g}\end{array}$ \\
\hline \multirow[t]{2}{*}{ A } & Wu-67 A-w & - & - & GW & GW & GW & GW & GW & GW \\
\hline & 8A-w & - & - & $\begin{array}{l}\text { WW } \\
\text { GW }\end{array}$ & $\begin{array}{l}\text { WW } \\
\text { GW }\end{array}$ & $\begin{array}{l}\text { WW } \\
\text { GW }\end{array}$ & $\begin{array}{l}\text { WW } \\
\text { GW }\end{array}$ & $\begin{array}{l}\text { WW } \\
\text { GW }\end{array}$ & $\begin{array}{l}\text { WW } \\
\text { GW }\end{array}$ \\
\hline B & 25 B-w & $\begin{array}{l}\text { GG } \\
\text { GW }\end{array}$ & GW & - & GiW & Giw & Giw & Giw & GW \\
\hline \multirow[t]{4}{*}{ C } & 32C-w & $\begin{array}{l}\text { GG } \\
\mathbf{G W}\end{array}$ & Giw & GW & - & - & - & Giw & GiW \\
\hline & 34C-w & GG & GW & ciw & $\dot{-}$ & $\cdot$ & $\cdot$ & civ & GW \\
\hline & JP-55C-w & GG & & & . & . & . & . & \\
\hline & & GW & GW & GW & - & - & - & GW & GW \\
\hline \multirow[t]{3}{*}{ D } & 3D-w & $\begin{array}{l}\text { GG } \\
\text { GW }\end{array}$ & giw & Gw & Giw & GiW & ciw & $\dot{-}$ & $\therefore$ \\
\hline & NC-64D-w & GG & & & . & . & · & . & \\
\hline & & GW & GW & GW & GW & GW & GW & - & \\
\hline
\end{tabular}

'WW' indicates the presence of pairs consisting of two white cells, hence intraclonal conjugation. ' GG' indicates the presence of pairs consisting of two green cells, hence intraclonal conjugation. ' $G W$ ' indicates the presence of pairs consisting of one white cell and one green cell, hence interclonal conjugation.

'- ' indicates an absence of pairs, hence stocks belong to the same mating type.

cluded that only cells of complementary types adhered within clumps. During the first $2 \mathrm{hr}$., the events of the mating reaction followed the normal pattern detailed by others (see Jennings, 1939; Wichterman, 1953). About $2 \mathrm{hr}$. after the initiation of the mating, the cells began to lose their ciliary stickiness and the large clumps disintegrated into pairs, each cell tightly joined to its mate along the opposing oral surfaces. Now for the first time illegitimate (green $\times$ green) as well as legitimate (green $\times$ white) pairs were observed. Unlike those formed earlier, these pairs were joined by 'holdfast unions' (Metz, 1947) and most of them could not be forced apart. The point to be stressed is this: legitimate interclonal conjugation proceeds from loose initial loose ciliary agglutinations to the formation of tightly joined and properly oriented pairs. However, intraclonal mating (Wu-67 $\times \mathrm{Wu}-67$ ) apparently occurs directly, omitting the stage of initial ciliary agglutinations; as will be shown 
later, it is dependent only on prior interclonal cell unions. Although cells of a given mating type are frequently packed next to one another during clumping, loose and randomly oriented intraclonal unions were not observed. Since the interaction of cells expressing complementary mating types results in loose ciliary unions and since no such unions were observed between two cells of stock $\mathrm{Wu}-67$, these intraclonal conjugations might be interpreted as illegitimate. The two experiments next to be described provide further evidence for this conclusion.

In the first experiment, a sexually reactive culture of $\mathrm{Wu}-67-\mathrm{g}$ was mixed with a chlorella-less culture of a complementary type. The Wu-67 $\times$ Wu-67 (green $\times$ green) pairs were isolated and immediately forced apart by repeatedly expelling the pair from a micropipette (Sonneborn, 1950). The viable members of such split pairs were re-isolated, allowed to multiply to form large cultures and subsequently tested for mating type. (As mentioned before, many pairs are firmly united and cannot be forced apart successfully; thus a certain amount of selection enters into the choice of cells to be tested.) All such cultures were found to consist exclusively of cells of mating type $\mathbf{A}$. Thus there was no evidence for an hereditary change of mating type associated with the induction of selfing.

In the second experiment split pairs were obtained in the manner described above, but immediately after the pairs had been disjoined mating-type tests on each member of the pair were begun. Each uncoupled cell was placed first in a culture of sexually reactive chlorella-less testers of mating type B. As soon as an initial mating reaction (ciliary agglutination) was observed between the green (Wu-67) member of the split pair and a white cell (or cells) of the complementary mating type, the Wu-67 cell was removed and placed in another drop, this containing white cells of type $\mathrm{C}$. When the Wu-67 cell reacted with cells of type $\mathrm{C}$, it was again removed and placed with cells of type $D$, and finally with cells of type $A$. Such a series of four tests was completed within 20 min. after the original Wu-67 $\times$ Wu-67 pair was split. The results appear in Table 3. Some cells could not be fully tested. Several died, apparently due to injury incurred during the process of separation. In other cases a cell from a split pair failed to react with two of the standard mating types, but this was not unexpected because the original pairs were obtained from clumps which were disintegrating due to the gradual loss of initial ciliary mating reactivity. These incomplete tests (split pairs numbered 6-10) provided no data contrary to those furnished by the cells which gave complete sets of tests. None of the cells showed a mating reaction with cells of type $A$; therefore none can be classified as belonging to a mating type other than $\mathbf{A}$.

The frequency of contact between cells of stock Wu-67 and individuals of a complementary mating type was varied by altering the cell population density (but not their total numbers) in reaction mixtures. The data in Table 4 show that both legitimate and illegitimate conjugations were favoured by higher cellular concentrations. However, in denser populations about $12 \%$ of all conjugations were illegitimate, while less than $2 \%$ of the pairs were illegitimate in more sparse populations. In another experiment, the ratio of $\mathrm{Wu}-67$ cells to those of a complementary type $(32 \mathrm{C}-\mathrm{w})$ was varied while the total population density was kept constant. It was immediately apparent that in mixtures wherein cells of one mating type are present in excess numbers, the masses of clumped cells which formed soon after mixture contained an excess of individuals of that type. When there was an 
Table 3. The mating types of cells from uncoupled Wu-67 $\times W u-67$ pairs. Each ex-pair member ( $I$ and $I I$ ) was tested against standard types $A, B, C, D$

(Key: ' + ' = mating reaction; ' - ' = no reaction; ' 0 ' $=$ cell died or was lost.)

\begin{tabular}{cccccc}
\multirow{2}{*}{$\begin{array}{c}\text { Split } \\
\text { pair }\end{array}$} & Cell & A & B & C & D \\
the indicated mating type & \\
I & I & - & + & + & + \\
& II & - & + & + & + \\
2 & I & - & + & + & + \\
& II & - & + & + & + \\
3 & I & - & + & + & + \\
& II & - & + & + & + \\
4 & I & - & + & + & + \\
& II & - & + & + & + \\
5 & I & - & + & + & + \\
& II & - & + & + & + \\
6 & I & 0 & + & + & + \\
& II & 0 & + & + & 0 \\
7 & I & - & + & + & + \\
& II & - & + & + & - \\
8 & I & $\mathbf{0}$ & + & + & 0 \\
& II & 0 & + & 0 & 0 \\
9 & I & - & + & - & - \\
& II & - & + & - & + \\
I0 & I & - & - & + & + \\
& II & - & + & + & -
\end{tabular}

excess of $32 \mathrm{C}$-w over $\mathrm{Wu}-67$ cells, the frequency of contacts between given individuals of Wu-67 and cells of the complementary mating type was greater than that occurring in mixtures set up with an excess of $\mathrm{Wu}-67$ cells. The results summarized in Table 5 are consistent with the idea that the effect of more frequent contacts with complementary cells, brought about by the mating reaction, was to increase the incidence of illegitimate conjugations.

Table 4. The effect of population density on the frequency of illegitimate conjugation (Wu-67 $\times W u-67$ pairs)

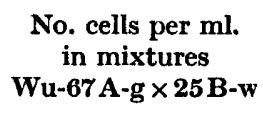

340

170

\begin{tabular}{|c|c|}
\hline \multicolumn{2}{|c|}{ Number of pairs } \\
\hline $\begin{array}{c}\text { Illegitimate } \\
(\text { green } \times \text { green) }\end{array}$ & $\underset{\text { (green } \times \text { white })}{\text { Legitimate }}$ \\
\hline 5 & 76 \\
\hline 5 & 45 \\
\hline 14 & 56 \\
\hline 8 & 54 \\
\hline 32 & 231 \\
\hline $\mathbf{1}$ & 25 \\
\hline $\mathbf{0}$ & 30 \\
\hline 1 & 38 \\
\hline 0 & 36 \\
\hline 2 & 139 \\
\hline
\end{tabular}


All attempts to induce illegitimate $\mathrm{Wu}-67 \times \mathrm{Wu}-67$ conjugations by breis or cellfree fluids from cultures of complementary types were unsuccessful. Nor could we find evidence for the existence of an 'inducing substance' released by sexuallyreacting cells. Sexual reactivity is a requisite for induced selfing; unreactive Wu-67 animals could not be induced to self, and unreactive cells of a complementary type did not induce illegitimate mating. Finally, when reactive cells of $\mathrm{Wu}-67$ were mixed with reactive cells of a non-complementary mating type (mating type $\mathbf{E}$, syngen 2), neither interstock nor Wu-67 conjugations occurred.

Genetic analyses of stock Wu-67 were virtually ruled out by the unfortunate fact that crosses involving this stock yield extremely high proportions of non-viable progeny (see Table 6).

Table 5. The effect of population composition on the frequency of illegitimate conjugation (Wu-67 $\times$ Wu-67 pairs)

\begin{tabular}{|c|c|}
\hline \multicolumn{2}{|c|}{ Approx. no. of cells mixed } \\
\hline Wu-67 A-g & $32 \mathrm{C}-\mathrm{w}$ \\
\hline 1200 & 200 \\
\hline 700 & 700 \\
\hline 200 & 1200 \\
\hline
\end{tabular}

\begin{tabular}{|c|c|c|}
\hline \multicolumn{2}{|c|}{ Number of pairs } & \multirow[b]{2}{*}{$\begin{array}{c}\text { Illegitimate pairs } \\
(\%)\end{array}$} \\
\hline $\begin{array}{c}\text { Illegitimate } \\
\text { (green } \times \text { green) }\end{array}$ & $\begin{array}{c}\text { Legitimate } \\
\text { (green } \times \text { white) }\end{array}$ & \\
\hline $\mathbf{0}$ & 165 & $\mathbf{0}$ \\
\hline 6 & 147 & 4 \\
\hline 5 & 58 & 8 \\
\hline
\end{tabular}

Table 6. The viability of exconjugant clones from legitimate and illegitimate matings involving stock $\mathrm{Wu}-67$

$\begin{array}{lcc}\text { Mating } & \begin{array}{c}\text { No. clones } \\ \text { studied }\end{array} & \begin{array}{c}\text { No. clones } \\ \text { viable }\end{array} \\ \text { Wu-67 A-g } \times 25 \text { B-w } & 282 & 3 \\ \text { Wu-67 A-g } \times 32 \text { C-w } & 84 & 0 \\ \text { Wu-67 A-g } \times 34 \text { C-w } & 110 & 1 \\ \text { Wu-67 A-g } \times 3 \text { D-w } & 88 & 0 \\ \text { Wu-67 } \times \text { Wu-67 } & 180 & 2\end{array}$

\section{DISCUSSION}

Stock Wu-67 is the only stock of Paramecium bursaria known to form pairs inter se following contacts with cells of complementary mating types. These intraclonal pairings can be termed illegitimate, for they evidently occur between cells expressing a common mating type. In sharp contrast, the intraclonal conjugations previously reported for $\boldsymbol{P}$. bursaria (Jennings, 1941), $P$. aurelia (Kimball, 1939; Sonneborn, 1947), P. multimicronucleatum (Sonneborn, 1957) and Tetrahymena pyriformis (Nanney \& Caughey, 1955) always resulted from the differentiation of individuals of complementary mating types within the selfing clone. Such conjugation does not differ in principle from the more familiar interclonal matings and may be termed legitimate. (Certain selfing clones of Tetrahymena described by Elliott \& Nanney, 1952, do not conform to this pattern.)

Weiss's (1960) model for cell specificity and selectivity appears to account for both legitimate and illegitimate conjugations in Paramecium. This model is based on a dualistic principle of action involving: (1) a specific primary reaction which serves to expose sites of reactivity by alteration of the cell surface; (2) a non-specific 
secondary reaction at the level of the exposed sites. The model assumes that the cell surface contains a network of protein molecules which acts as a 'barrier' to cell union, transport and transmission. However, specific end groups on the protein molecules react with complementary groups on an extraneous carrier (particle or cell) and thus are reoriented from a tangential position to one radial to the cell surface. This reorientation causes 'breaches' in the barrier allowing the passage of materials or currents. Metz (1954) showed that cells of complementary mating types possessed specific and complementary sex substances on their surfaces whose union or interaction led to the initial adhesion of potential conjugants and provided a basis for the observed specificity of the primary mating reaction. Weiss's model suggests the next events of conjugation. The interaction of the specific sex substances results in their reorientation thereby exposing secondary non-specific holdfast sites; then, in accord with many observations, cells united at holdfast sites normally proceed through conjugation.

Weiss's model provides an explanation for the well-documented fact that paramecia which unite in conjugation belong to complementary types, for the initial intimate contact brought about by the specific interactions of surface molecules serves to insure heterotypic holdfast unions. By assuming that the non-specific holdfast sites of cells from stock Wu-67 are more readily (or earlier) exposed by ciliary contact with a legitimate prospective mate, illegitimate unions will be expected to occur when two $\mathrm{Wu}-67$ cells are fortuitously pressed together during the mass clumping phase of mating.

The hypothesis seems to account in a satisfactory way for the facts concerning stock Wu-67. Firstly, a mating reaction involving cells of Wu-67 and a complementary type is a necessary condition for illegitimate conjugation. Secondly, cells of Wu-67 which have begun to conjugate illegitimately are unchanged with respect to mating type specificity (all are type A). Thirdly, Wu-67 $\times$ Wu-67 pairs first appear when clumps disintegrate, and the mates are always united by one or more of the three holdfast sites known for Paramecium. The fact that $\mathrm{Wu}-67 \times \mathrm{Wu}-67$ pairs are more frequent in mixtures in which there is an excess of cells of a complementary type may mean that Wu-67 cells must be in repeated or prolonged contact with cells of a complementary type in order to precociously uncover the holdfast site.

The immediate value of the hypothesis is that it appears to account for a number of observations concerning irregular mating reactions in ciliates. For example, the hypothesis predicts that a block might occur between the primary specific reaction and the secondary non-specific reaction. As Sonneborn (1942) and Metz (1954) stressed, the behaviour of a mutant stock of Paramecium aurelia indicates the existence of discrete steps in the reactions leading to conjugation. A block CM ( = 'can't mate') evidently occurs after the primary interaction of mating-type substances. Thus cell agglutination proceeds normally but the $\mathbf{C M}$ cells are unable to complete conjugation because the secondary non-specific sites are effectively unavailable.

Other observations reveal the fact that the initial cellular agglutinations which are brought about by mating-type specificity differences are not inevitably followed by the formation of tightly joined pairs and so are consistent with the notion of separable primary and secondary interactions in conjugation. For example, both nutritive condition and life-cycle stage are factors known to determine whether or 
not the loose cellular aggregates characteristic of the early phase of mating will yield tightly joined pairs which complete conjugation.

Hiwatashi (1958) and Miyake (1958, 1960) showed that chemical agents can induce pair formation and conjugation in Paramecium irrespective of mating-type specificity. Particularly striking was the demonstration that chemicals induced matings between individuals of separate syngens and species, as well as intraclonal selfing. Following chemical treatment pairs were formed directly, the mates attached by their holdfast sites; since the initial stages of normal mating reactions (loose ciliary unions and the formation of clumps of reacting cells) are omitted, it does not seem likely that such conjugation is a consequence of specific mating-type changes. Chemical treatment may remove the barrier formed by molecules concerned with primary specific mating-type complementarity and so permit the secondary non-specific mating-type holdfast unions to occur directly.

Although the available data seem to fit Weiss's hypothesis, other kinds of explanations are not excluded. Dr T. M. Sonneborn in a personal communication, suggested that the primary specific mating reaction serves to trigger another internal cellular reaction which leads to the non-specific receptivity of the cortical surface of the cell; firm cell attachments and conjugation occur when the activated cortical areas of cells are brought together. On this view the secondary reaction is not a direct mechanical consequence of the primary reactions of complementary molecules as Weiss's model would hold. Future research should be directed towards an understanding of the relationship between the primary and secondary mating reactions.

Finally, it must be pointed out that the mechanism proposed here for illegitimate pairing in Paramecium bursaria, and for the chemical induction of selfing described by Hiwatashi and by Miyake for other species, may not be applicable to the induction of pseudo-selfing reported by Sonneborn and by Metz. The latter workers were able to show that cells which have been temporarily united with individuals of a complementary mating type behaved as if they had acquired that mating-type specificity in the course of contact. Thus a transitory shift of mating type may occur in these cases. But in $P$. bursaria both mates need to be 'activated' by contact with cells expressing a complementary type in order that illegitimate conjugation may occur; this is certainly not the case for the pseudo-selfers of Sonneborn and Metz. Although the phenomena may appear superficially similar they probably call for quite different explanations.

Induced selfing of the kind reported for stock Wu-67 is apparently extremely rare in Paramecium bursaria. No evidence for this phenomenon was observed among at least 100 clones studied by Jennings (see Sonneborn, 1947) and others (Ehret, 1953; Siegel, 1960; Wichertman, 1953). Therefore homotypic matings are presumably unimportant in the evolution and genetic analyses of this organism.

We wish to thank Drs G. H. Beale, A. Miyake, T. M. Sonneborn and P. Weiss for their advice in the preparation of this paper.

This work was supported by grants from the National Science Foundation and by Cancer Research Funds of the University of California. 


\section{REFERENCES}

Ehret, C. F. (1953). An analysis of the role of electromagnetic radiations in the mating reaction of $P$. bursaria. Physiol. Zool. 26, 274.

Eldrotr, A. M. \& Nanney, D. L. (1952). Conjugation in Tetrahymena. Science, 116, 33.

Hiwatashi, K. (1955). Studies on the conjugation of $P$. caudatum. VI. On the nature of the union of conjugation. Sci. Rep. Tohoku Univ., 4th Ser. Biol. 21, 207.

Hrwatashr, K. (1958). Artificial induction of conjugation by EDTA in $P$. caudatum. 29th Annual Meeting Zoological Society of Japan.

Jennings, H. S. (1939). Genetics of P. bursaria. I. Mating types and groups, their interrelations and distribution: mating behavior and self sterility. Genetics, 24, 202.

Jennings, H. S. (1941). Genetics of $P$. bursaria. II. Self-differentiation and self-fertilization of clones. Proc. Amer. phil. Soc. 85, 25.

Krmball, R. F. (1939). Change of mating type during vegetative reproduction in P. aurelia. J. exp. Zool. 81, 165.

METz, C. B. (1947). Induction of 'pseudo-selfing' and meiosis in $P$. aurelia by formalinkilled animals of opposite mating type. J. exp. Zool. 105, 115.

Metz, C. B. (1954). Mating substances and the physiology of fertilization in Ciliates. In Sex in Microorganisms, Symp. Amer. Ass. Advanc. Sci. p. 284.

Mryake, A. (1956). Physiological analysis of the life cycle of the Protozoa. III. Artificial induction of selfing conjugation by chemical agents in $P$. caudatum. $J$. Inst. Polyt., Osaka, Ser. D, 7, 14.

MrYAKe, A. (1958). Induction of conjugation by chemical agents in $P$. caudatum. J. Inst. Polyt., Osaka, Ser. D, 9, 251.

MiYake, A. (1960). Artificial induction of conjugation by chemical agents in $P$. aurelia, P. multimicronucleatum, P. caudatum and between them. J. Protozool. 7 (Supplement), 15 (Abstract).

NanNey, D. L. \& Caughey, P. A. (1955). An unstable nuclear condition in Tetrahymena pyriformis. Genetics, 40, 388.

Sieged, R. W. (1958). An intrafertile colony of P. bursaria. Amer. Natur. 92, 253.

Siegel, R. W. (1960). Hereditary endosymbiosis in P. bursaria. Exp. Cell Res. 19, 239.

Siegel, R. W. \& LARIson, L. L. (1960). The genic control of mating types in $P$. bursaria. Proc. Nat. Acad. Sci., Wash. 46, 344.

Siegel, R. W. \& Larison, L. L. (1960). Induced illegitimate mating in P. bursaria. Anat. Rec. 138, 383 (Abstract).

SonNEBorn, T. M. (1942). Evidence for two distinct mechanisms in the mating reaction of $P$. aurelia. Anat. Rec. 84, 542 (Abstract).

Sonneborn, T. M. (1947). Recent advances in the genetics of Paramecium and Euplotes. Advanc. Genet. 1, 263.

Sonnebonn, T. M. (1950). Methods in the general biology and genetics of $P$. aurelia. J. exp. Zool. 113, 87.

Sonnebonn, T. M. (1957). Diurnal change of mating type in Paramecium. Anat. Rec. 128, 626 (Abstract).

WEIss, P. (1960). Molecular reorientation as unifying principle underlying cellular selectivity. Proc. Nat. Acad. Sci., Wash. 46, 993.

Wichterman, R. (1953). The Biology of Paramecium. New York: McGraw-Hill. 